\title{
Impact of socioeconomic risk factors on the seroprevalence of cytomegalovirus infections in a cohort of pregnant Polish women between 2010 and 2011
}

\author{
W. Wujcicka $\cdot$ Z. Gaj $\cdot$ J. Wilczyński $\cdot$ W. Sobala • \\ E. Śpiewak • D. Nowakowska
}

Received: 18 March 2014 / Accepted: 20 May 2014 /Published online: 6 June 2014

(C) The Author(s) 2014. This article is published with open access at Springerlink.com

\begin{abstract}
The purpose of this investigation was to perform an evaluation of the prevalence and socioeconomic risk factors for human cytomegalovirus (HCMV) infections in a cohort of Polish pregnant women between 2010 and 2011. HCMVspecific IgG and IgM antibody levels were assayed with enzyme-linked immunosorbent assay (ELISA) tests in serum samples collected from 1,250 pregnant women attending outpatient obstetric clinics and hospitalized at two hospitals in Lodz. The seroprevalence of anti-HCMV IgG and IgM antibodies was 62.4 and $2.2 \%$, respectively, and differed significantly between age-stratified groups $(p \leq 0.05)$. The highest $\mathrm{IgG}$ prevalence was observed in women above 36 years of age (76.2\%) and IgM in adolescent women aged 16-20 years $(6.0 \%)$. Of the various socioeconomic factors, age above 36 years, basic and professional education, and offspring were significantly associated with HCMV IgG prevalence rates (PRs; $1.89,1.80$, and 1.56, respectively). Financial status, occupational risk related to contact with children, and transfusions were not related to the prevalence of $\operatorname{IgG}$ antibodies.
\end{abstract}

W. Wujcicka and Z. Gaj contributed to the study equally.

W. Wujcicka·Z. Gaj· J. Wilczyński • D. Nowakowska $(\bowtie)$ Department of Fetal-Maternal Medicine and Gynecology, Polish Mother's Memorial Hospital Research Institute, 281/289 Rzgowska Street, Lodz 93-338, Poland

e-mail: dnowakowska@yahoo.com

J. Wilczyński • D. Nowakowska

Department of Fetal-Maternal Medicine and Gynecology, Third Chair of Gynecology and Obstetrics, Medical University of Lodz, 281/289 Rzgowska Street, Lodz 93-338, Poland

\section{W. Sobala}

Department of Environmental Epidemiology, Institute of

Occupational Medicine, Lodz, Poland

\section{E. Śpiewak}

Department of Microbiology, Polish Mother's Memorial Hospital Research Institute, Lodz, Poland
The IgM prevalence was not associated with any of the analyzed risk factors. A slightly higher prevalence was observed in women who were transfused in the past, but the relationship was not significant. The current data have revealed a decrease in HCMV IgG seroprevalence in our region during recent years (62.4 vs. $76.7 \%$ ). Basic and professional education, as well as bringing up offspring, were determined as significant risk factors for HCMV infections in Polish pregnant women [risk ratio (RR) 1.20 and 1.17, respectively], suggesting that the primary and secondary prophylaxis of cytomegaly is necessary during pregnancy, even if screening is not mandatory.

\section{Introduction}

Human cytomegalovirus (HCMV) is the most common factor of intrauterine viral infections, transmitted in urine, blood, saliva, by breastfeeding, genitourinary tract secretions, feces, tears, and transplanted organs [1-7]. HCMV infections may be acquired prenatally, perinatally, or postnatally, and can cause permanent physical sequelae, with an increased risk of infant mortality. Congenital infections occur via vertical transmission of the virus by a hematogenous route from infected pregnant woman to the fetus via the placenta [6]. The incidence rates of viral transmissions from mothers with primary infections during pregnancy to their fetuses are estimated to be in the range $30-40 \%$, while in those with recurrent infections, the range is $0.2-2.2 \%$ [8-12]. The diagnosis of cytomegaly is based mostly on serological tests during pregnancy. The primary infection is defined as HCMV IgG seroconversion during pregnancy but, in most cases, the distinction between primary and non-primary maternal cytomegaly is very difficult, due to the lack of data on the preconception serologic status. The presence of specific HCMV IgM antibodies and the low IgG avidity do not always indicate recent primary 
infection $[8,13]$. In most cases, systematic ultrasound is not sensitive enough to detect signs of fetal cytomegaly beside its most characteristic symptoms, such as microcephaly, ventriculomegaly, increased periventricular echogenicity, and calcifications $[8,14]$.

Congenital HCMV infections during the first trimester of pregnancy are more likely to cause a severe form of the disease, but symptomatic cases were also reported, when transmission occurred in the third trimester of pregnancy [15]. Approximately 10 to $15 \%$ of in utero infected newborns demonstrate clinical symptoms observed in various organs and systems and $85-90 \%$ of these children will develop some degree of psychomotor and mental retardation, including visual impairment and sensorineural hearing loss [8, 16]. Children born with asymptomatic HCMV infections (85$90 \%$ ) may also acquire cytomegaly-related symptoms, such as hearing impairment and difficulties in learning during the first months or, more often, in the first few years of life $[6,8,11]$.

The prevalence of HCMV IgG antibodies varies between continents and countries, ranging from 40 to $100 \%$ [7, 17, 18]. The prevalence rate of $76.7 \%$ was observed in Polish pregnant women between the years 1999 and 2009, being one of the highest in Europe, alongside such countries as Sweden or Italy (72 and $68 \%$, respectively) [3, 17, 19]. So far, studies in different countries have revealed elevated prevalence rates of congenital HCMV, related to non-white race, increased sexual activity with multiple partners, age below 25 years, an increased age of pregnant women, multiparity, preschool children in the household, and occupational exposure to children, as well as lower socioeconomic status (SES) [7, 20-22]. The reported SES risk factors for increased HCMV prevalence included a lower level of education and lower incomes of pregnant women [23-26].

In the reported study, we investigated the prevalence of specific anti-HCMV IgG and IgM antibodies and the socioeconomic risk factors of HCMV infections in a group of pregnant women from Poland attending outpatient obstetric clinics and hospitalized between 2010 and 2011 at the Polish Mother's Memorial Hospital Research Institute (PMMHRI) and at the Ludwig Rydygier Hospital in Lodz.

\section{Materials and methods}

The study included 1,250 randomly selected, newly registered pregnant women who attended the outpatient obstetric clinics and were treated at the PMMHRI and the Ludwig Rydygier Hospital between April, 2010 and March, 2011. The cohort, hospitalized at the PMMHRI, consisted of pregnant women from the Lodz Province and from other Polish regions, as the PMMHRI houses a reference perinatal care center.
Serological tests

Blood samples were obtained from pregnant women twice during pregnancy (at the 12th-15th and the 30th-34th gestational weeks) and within a day from childbirth. Blood specimens of $2.6 \mathrm{ml}$ were collected from participants, who signed an informed consent form. The blood was collected into sterile, nonanticoagulated tubes. The collected samples were centrifuged at $3,000 \times \mathrm{g}$ for $10 \mathrm{~min}$ and serum fractions were stored at $-20^{\circ} \mathrm{C}$.

Serum anti-HCMV IgG and IgM antibody levels were assayed by enzyme-linked immunosorbent assay (ELISA) tests (LIAISON ${ }^{\circledR}$, DiaSorin, Italy), and seropositivity was determined, using the manufacturer's guidelines. The screening was performed using a LIAISON ${ }^{\circledR}$ immunoassay analyzer. All samples were considered as IgG- or IgM-positive when the antibody levels were $>0.4 \mathrm{IU} / \mathrm{ml}$ and $>30 \mathrm{AU} / \mathrm{ml}$, respectively. For IgG avidity assessment, the indexes $<0.300$ were interpreted as low avidity suggesting recent infection, whereas the indexes $\geq 0.300$ were interpreted as high avidity. Pregnant women were considered as probably recently infected in cases where specific IgG were elevated, IgM were present, and IgG avidity was low. The kinetics of the specific antibodies was of great importance. In those women, the presence of HCMV DNA was checked using a real-time Q PCR assay for the viral UL55 gene in blood, urine, and amniotic fluid specimens [4]. DNA isolation and real-time Q PCR were carried out at the Laboratory of Molecular Virology and Biological Chemistry, Institute of Medical Biology, Polish Academy of Sciences in Lodz.

All participants completed a structured questionnaire, including data on the demographic and socioeconomic status, as well as previous exposure to blood transfusion. The pregnant women subjectively classified their financial status into one of four categories: bad, average, good, and very good. The study had been approved by the Ethical Committee of the PMMHRI in Lodz and all the women participating in the study signed the consent form.

\section{Statistical analysis}

The seroprevalence rates of anti-HCMV IgG and IgM antibodies were assessed by means of descriptive statistics. Relationships were determined between the prevalence rates of HCMV and various socioeconomic factors, including age, level of education, offspring, financial status, and a risk of occupational contact with children and transfusions, using cross-tabulation and Pearson's Chi-squared test. Yates' continuity correction for the Chi-squared test was used to determine differences in the risk of HCMV infections between pregnant women with and without children at home. Fisher's exact test for count data was used to determine the significance of the differences in HCMV IgM prevalence rates 
among pregnant women with different socioeconomic status. For all socioeconomic factors, the prevalence rates and risk ratios (PRs and RRs, respectively) of HCMV $\operatorname{IgG}$ were assessed, using a binary logistic regression model. All results were determined as being statistically significant at the significance level of $p \leq 0.05$. Data were analyzed using the Stata v.11 software (StataCorp, College Station, TX, USA).

\section{Results}

Prevalence of $\mathrm{IgG}$ antibodies in different age groups

The study cohort consisted of 1,250 pregnant women, aged 16-45 years, among whom $62.4 \%(780 / 1,250)$ were determined as HCMV IgG seropositive (see Table 1). The total population of women was grouped into five age classes. The prevalence rate was significantly associated with the age of the patients $(p=0.0069)$, with the highest value of $76.2 \%$ (99/ 130) observed in pregnant women aged $\geq 36$ years, and the lowest prevalence rate of $58.5 \%(298 / 509)$ in women aged 26-30 years. A slightly higher prevalence rate of $66.0 \%$ (33/ 50) was found in patients aged 16-20 years. A significant association between HCMV prevalence and age was observed among pregnant women above 36 years of age $[\mathrm{PR}=1.89$; $95 \%$ confidence interval (CI) 1.17-3.07].

\section{$\mathrm{IgG}$ prevalence in various socioeconomic groups}

The study population was classified into three groups, according to the education level (see Table 1). Appropriate data were obtained for 1,180 pregnant women. Higher education was recorded in $56.5 \%(667 / 1,180)$ of women, secondary education in $31.3 \%(369 / 1,180)$, and primary and vocational education was reported by $12.2 \%(144 / 1,180)$. The HCMV prevalence rate differed significantly among particular groups with various education levels $(p=0.0017)$. The prevalence rate decreased with increasing education level, ranging from $72.9 \%(105 / 144)$ in the group with primary and vocational education to $58.0 \%(387 / 667)$ in the group with university education. A significant association with the prevalence rate of infection was observed for secondary, primary, and vocational education $(\mathrm{PR}=1.34 ; 95 \%$ CI $1.00-1.79$ and $\mathrm{PR}=1.80$; $95 \%$ CI 1.14-2.83, respectively).

The group of 1,170 pregnant women was also described in relation to offspring in the household (see Table 1). In the study population, $40.9 \%(479 / 1,170)$ of pregnant women had children. The prevalence rate differed significantly among the groups of patients with and without children $(p \leq 0.0001)$. The differences stayed significant after Yates' continuity correction. In women with offspring, the prevalence rate of infection was 1.56 times higher than in those without children: $69.5 \%$
(333/479) vs. $57.3 \%$ (396/691) (95 \% CI 1.19-2.05; $p=0.0012)$. Additionally, the cohort was evaluated according to the financial status and risk of occupational contact with children, which was characteristic for professional groups, such as school teachers, health care workers, social and community workers, as well as sales staff. Neither the financial status nor the occupational contact with children and blood transfusions influenced the prevalence rate $(p=0.5115$, $p=0.4843$, and $p=0.4247$, respectively; see Table 1 ). Considering the financial status, the highest prevalence of infection was observed among the pregnant women with average or good financial status $(63.5 \%)$, and the lowest prevalence rate among women with the best financial status $(53.9 \%)$. The prevalence rate among patients with or without the occupational risk related to contact with children was $63.3 \%$ (236/373) and $61.5 \%$ (491/799), respectively. Pregnant women with or without blood transfusions in their history had prevalence rates of $56.5 \%(26 / 46)$ and $62.3 \%$ (707/1,134), respectively. However, the observed differences were not significant.

Out of the various socioeconomic factors, the level of education and offspring in the household were determined as being significantly associated with HCMV infection rates ( $p=0.0276$ and $p=0.0016$, respectively). The highest risk of infection was observed in pregnant women with primary and vocational education (RR 1.20, $95 \%$ CI 1.05-1.37). A slightly lower (1.17) RR (95 \% CI 1.06-1.29) was found in women with offspring. The age of pregnant women, their financial status, the risk of occupational contact with children, and blood transfusions in their history were not associated with HCMV infections ( $p=0.0910, p=0.3469, p=0.6520$, and $p=0.2004$, respectively). However, the age of pregnant women tended to be an important risk factor of HCMV infections, with the highest RR observed in patients above 36 years of age (1.20, $95 \%$ CI 1.06-1.36).

\section{Prevalence of IgM antibodies}

The prevalence of $\operatorname{IgM}$ antibodies was $2.2 \%(28 / 1,250$; see Table 2) and, similarly to IgG, it was significantly associated with the patients' age ( $p=0.0174)$. The highest prevalence rate of $6.0 \%(3 / 50)$ was observed in pregnant women at the age of 16-20 years, and a little lower (4.6\%) (6/130) in those aged $\geq 36$ years. Similarly to $\mathrm{IgG}$ antibodies, the lowest prevalence rate of $1.0 \%(5 / 509)$ was found in the group aged 26 30 years.

IgM prevalence in various socioeconomic groups

The prevalence of specific IgM in the study cohort reached $2.2 \%$ and was independent of any of the analyzed socioeconomic factors. According to the level of education, similar prevalence rates $(2.0 \%)$ were observed $(p=1.0000$; see 


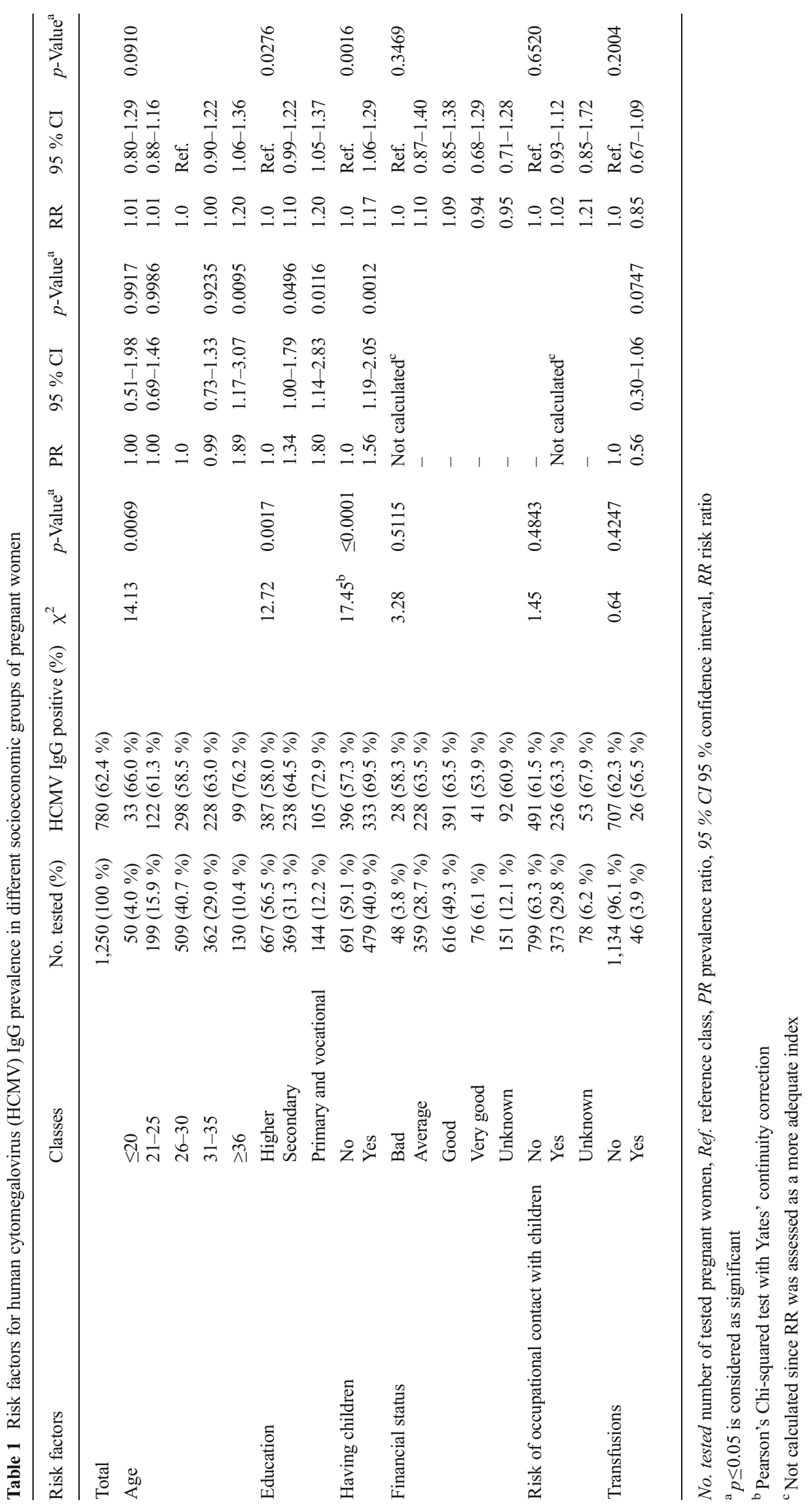


Table 2 HCMV IgM prevalence and risk factors in the studied cohort of pregnant women

\begin{tabular}{llr}
\hline Risk factors & Classes & $\begin{array}{r}\text { HCMV IgM } \\
\text { positive }(\%)\end{array}$ \\
\hline Total & & $28(2.2 \%)$ \\
Age & $\leq 20$ & $3(6.0 \%)$ \\
& $21-25$ & $4(2.0 \%)$ \\
& $26-30$ & $5(1.0 \%)$ \\
& $31-35$ & $10(2.8 \%)$ \\
Education & $\geq 36$ & $6(4.6 \%)$ \\
& Higher & $14(2.1 \%)$ \\
Having children & Secondary & $7(1.9 \%)$ \\
& Primary and vocational & $3(2.1 \%)$ \\
Financial status & No & $15(2.2 \%)$ \\
& Yes & $10(2.1 \%)$ \\
& Bad & $1(2.1 \%)$ \\
Transfusions & Average & $5(1.4 \%)$ \\
& Good & $16(2.6 \%)$ \\
& Very good & $2(2.6 \%)$ \\
contact with children & Unknown & $4(2.6 \%)$ \\
& No & $16(2.0 \%)$ \\
& Yes & $9(2.4 \%)$ \\
& Yes & $23(2.0 \%)$ \\
& & $2(4.3 \%)$ \\
\hline
\end{tabular}

Table 2). The prevalence rate of about $2.0 \%$ was not correlated either with offspring or with the occupational risk of contact with children ( $p=1.0000$ and $p=0.4529$, respectively). Taking into account the financial status, the prevalence rate of IgM varied from 1.4 to $2.6 \%$ between classes, but the differences were not significant $(p=0.6863)$. Pregnant women with transfusions in their history presented with slightly higher prevalence rates than those without such events, but the relationship was non-significant $[4.3 \%(2 / 46)$ vs. $2.0 \%(23 /$ $1,134) ; p=0.2544)]$.

\section{Discussion}

The seroprevalence of anti-HCMV IgG antibodies differs throughout the world, ranging from 40 to $100 \%[7,17,18]$. The highest prevalence rates were reported in South America, Africa, and Asia [6, 20]. In Europe, the lowest prevalence rates were shown for pregnant women in the Netherlands (41\%), followed by France (46\%) and the United Kingdom (49\%) [27-29]. Higher prevalence rates were observed in Belgium and Finland (50-60\%) [30, 31]. In the reported study, we observed a prevalence rate of $62.4 \%$ in the cohort of 1,250 pregnant women. Given the prevalence rate of
$76.7 \%$ observed in Polish pregnant women hospitalized at the same department in the earlier period between 1999 and 2009, the current data revealed a decrease in the HCMV prevalence rate in the recent years [3], being similar to that for pregnant women in Spain (57\%), Norway (60\%), and Italy $(68 \%)$. Due to that reason, Poland can be placed among the European countries with moderate prevalence rates [17, $32,33]$. Higher prevalence values were observed in Turkey, ranging from $94.9 \%$ in the South to $96.4 \%$ in the North of the country $[18,34]$.

Evaluating the age of pregnant women in our study cohort, age above 36 years was the most important factor $(\mathrm{PR}=1.89)$ associated with HCMV prevalence. A significantly higher prevalence rate was observed in women above 36 years old than in younger ones, aged $26-30$ years (76.2 vs. $58.5 \%$ ). Similarly, higher prevalence rates for older pregnant women were observed in the British Isles, Italy, India, and Australia $[23,25,26,35]$.

In our study, the age of pregnant women also tended to be a risk factor of HCMV infections, with the highest risk ratio $(\mathrm{RR}=1.20)$ observed in women older than 36 years. The lack of statistical significance for the relationship between the age of pregnant women and the prevalence rate of infection possibly resulted from the relatively small number of pregnant women above 36 years of age, compared to the number of women aged 26-30 and 31-35 years. By contrast, the reports from studies on Northern Italian pregnant women have indicated no association between HCMV prevalence and patient age [17], which might have resulted from the low number of pregnant women in the youngest and oldest study groups (1.7 and $3.2 \%$ of the study cohort, respectively) [17]. In our study cohort, the prevalence rate in the youngest pregnant women aged 16-20 and 21-25 years was higher than that observed among women aged $26-30$ years ( 66.0 and $61.3 \%$ vs. $58.5 \%$, respectively). One possible explanation for the relatively high prevalence, observed in the youngest groups, could refer to the small number (4.0 and $15.9 \%$ of the whole cohort, respectively). However, the young age of pregnant women below 25 years of age, also reported in other studies, seems to be an important reason as well $[22,28]$.

Beside the region and age, other socioeconomic risk factors for HCMV infections have also been reported [21, 24, 36]. Higher prevalence rates in correlation with lower socioeconomic status were determined in pregnant women from Finland (60.9 vs. $76.4 \%$ ) and India (63.4 vs. $96.9 \%$ ) [24, 25]. A significant influence of this factor on the prevalence rates of the infection was also observed in the British Isles and Italy $[23,26]$. In our study cohort, we estimated a significant influence of the education level on the HCMV prevalence rate. The highest prevalence and risk of HCMV infection were characteristic for pregnant women with primary and vocational education (72.9 \% vs. 64.5 and $58.0 \%$ for primary and vocational vs. secondary and higher education, respectively; 
$P R=1.80, R R=1.20)$. A slightly lower influence on the prevalence rate of HCMV infection was observed for women with secondary education $(\mathrm{PR}=1.56)$. Since no other study has yet been performed to investigate the relationships between education level and the prevalence of HCMV, further research on the role of education as a risk factor of HCMV infections in pregnant women seems to be challenging and necessary.

HCMV prevalence among pregnant women might also be affected by having children [21, 25, 28]. In our study, we observed a significantly higher prevalence of HCMV infection in pregnant women with offspring than in those without children $(69.5 \%$ vs. 57.3 ; $\mathrm{PR}=1.56)$. It is consistent with the differences in the prevalence rates reported for pregnant women from India $(96.0,93.1$, and $66.7 \%$ for women having $\geq 3,1-2$, and no children, respectively) and the British Isles (from 66.2 to $46.4 \%$ vs. $38.9 \%$ for women having $4-1$ vs. those without children, respectively) $[25,26,36]$. In addition, our study also showed having children as a significant risk factor of HCMV infections during pregnancy $(\mathrm{RR}=1.17)$. Considering the financial status, we noticed the lowest HCMV prevalence among women with the best status (53.9 vs. $58.3 \%$ in women with very good vs. bad status, respectively). Fairly similar HCMV IgG seroprevalences were observed among pregnant women in Norway, where low family income was associated with higher CMV IgG seropositivity compared to high family incomes [62.9 vs. $53.8 \%$; odds ratio $(\mathrm{OR})=1.46,95 \%$ CI 1.00 to 2.12] [32]. However, in our study, the highest prevalence of HCMV infection was observed in pregnant women with good and average financial status $(63.5 \%)$, which may suggest the lack of influence of the economic status on HCMV infections in our cohort.

In the reported study, we also analyzed the occupational contact with children and blood transfusions as possible risk factors of HCMV infections. However, none of them was associated with HCMV prevalence rate. So far, the previously reported results related to the influence of occupational contact with children on HCMV prevalence rates were contrary to our observations [21, 37-40]. Based on those studies, we suggest that occupational contact with children is a population-dependent risk of HCMV infections. The observed discrepancies might originate from other factors, including hygiene behaviors and the age of children, cared for by the pregnant women included in the study [37, 41]. Accordingly to the role of transfusions in HCMV infections, we indicated a lack of any association between these factors investigated in our pregnancy cohort. This is similar to the relationship showed for multitransfused patients from Bangladesh [42]. No other papers have focused on transfusions as a risk factor of HCMV infections, although studies on HCMV prevalence among blood donors have been performed [43-45].

In this paper, we also analyzed the seroprevalence of antiHCMV IgM antibodies. In the studied cohort, the IgM prevalence rate was $2.2 \%$. Similar prevalence rates were also reported for pregnant women in Finland (4.0 \%), Australia $(5.5 \%)$, and France $(5.7 \%)[24,27,35]$. In the case of the French cohort, the IgM prevalence rate of $5.7 \%$ was characteristic for HCMV-IgG seropositive women, while for the whole study cohort, the IgM prevalence rate was $2.7 \%$, being similar to the prevalence observed among Polish pregnant women [27]. In addition, both our and French serological screenings were performed by means of the same laboratory tests [27]. In our study, we observed a significant association of the IgM prevalence with patient age, with changes in age-stratified prevalence rates similar to those observed for IgG antibodies. However, no current studies showed any association between age and the HCMV IgM prevalence rates $[39,40,46]$. We suggest that the relatively low IgM prevalence rates, reported in various populations, may have been responsible for the observed discrepancies. In the population of US pregnant women aged 12-49 years, the IgM prevalence rate was $3.0 \%$, but stayed relatively flat across the age groups [46]. Despite the fact that, in our cohort, age-associated differences in the IgM prevalence rates were observed, the lack of a significant age-related trend was fairly distinctive [46].

Similarly to other studies, no associations were found between the IgM prevalence rates and other risk factors, including education level, offspring, financial status, and the occupational risk of contact with children [24, 27, 47]. We suggest that the lack of relationships might be possibly caused by the relatively low seroprevalence of $\operatorname{IgM}$ in the study population $(2.2 \% ; 28 / 1,250)$. It seems plausible that only a large cohort study might show the risk factors influencing the prevalence rate of the IgM antibodies. The IgM prevalence tended to be higher in pregnant women with transfusions in their history than in those without transfusion events (4.3 vs. $2.0 \%$ ). The lack of significance in the relationship observed in our study might have resulted from the small number of transfused women $(3.9 \%, 46 / 1,180)$. In Bangladesh, a significant increase was observed in the seroprevalence of IgM antibodies for multitransfused patients, showing transfusions as a possible risk factor of HCMV infections during pregnancy [42].

In comparison with other European pregnancy populations, the prevalence of IgG anti-HCMV in the Polish pregnancy cohort is high. Primary and vocational education, having children, and age above 36 years are most serious risk factors of HCMV infections during pregnancy. This indicates the primary prophylaxis to increase the awareness of the risks, related to HCMV infections, in pregnancy as an extremely important measure.

Acknowledgments This work was supported, in part, by Iceland, Liechtenstein, and Norway through the EEA Financial Mechanisms and the Norwegian Financial Mechanism and Polish budget funds for research and science, project no. PL0270 'Prenatal and perinatal human cytomegalovirus infections'. 
Conflict of interest The authors declare that they have no conflict of interest.

Open Access This article is distributed under the terms of the Creative Commons Attribution License which permits any use, distribution, and reproduction in any medium, provided the original author(s) and the source are credited.

\section{References}

1. Cannon MJ (2009) Congenital cytomegalovirus (CMV) epidemiology and awareness. J Clin Virol 46(Suppl 4):S6-S10

2. Cordier AG, Guitton S, Vauloup-Fellous C, Grangeot-Keros L, Benachi A, Picone O (2012) Awareness and knowledge of congenital cytomegalovirus infection among health care providers in France. J Clin Virol 55(2):158-163

3. Gaj Z, Rycel M, Wilczyński J, Nowakowska D (2012) Seroprevalence of cytomegalovirus infection in the population of Polish pregnant women. Ginekol Pol 83(5):337-341

4. Paradowska E, Studzińska M, Nowakowska D, Wilczyński J, Rycel M, Suski P, Gaj Z, Kaczmarek B, Zbróg Z, Leśnikowski ZJ (2012) Distribution of UL144, US28 and UL55 genotypes in Polish newborns with congenital cytomegalovirus infections. Eur J Clin Microbiol Infect Dis 31(7):1335-1345

5. Syggelou A, Iacovidou N, Kloudas S, Christoni Z, Papaevangelou V (2010) Congenital cytomegalovirus infection. Ann N Y Acad Sci 1205:144-147

6. Britt W (2011) Cytomegalovirus. In: Remington JS, Klein JO (eds) Infectious diseases of the fetus and newborn infant. Saunders, Philadelphia, pp 707-756

7. Ornoy A, Diav-Citrin O (2006) Fetal effects of primary and secondary cytomegalovirus infection in pregnancy. Reprod Toxicol 21(4): 399-409

8. Benoist G, Leruez-Ville M, Magny JF, Jacquemard F, Salomon LJ, Ville Y (2013) Management of pregnancies with confirmed cytomegalovirus fetal infection. Fetal Diagn Ther 33(4):203-214

9. Hollier LM, Grissom H (2005) Human herpes viruses in pregnancy: cytomegalovirus, Epstein-Barr virus, and varicella zoster virus. Clin Perinatol 32(3):671-696

10. Nelson CT, Demmler GJ (1997) Cytomegalovirus infection in the pregnant mother, fetus, and newborn infant. Clin Perinatol 24(1): $151-160$

11. Rycel M, Gaj Z, Wilczyński J, Paradowska E, Studzińska M, Suski P, Nowakowska D (2013) Evaluation of the association between maternal HCMV viremia and the course of pregnancy and neonatal outcome. Ginekol Pol 84(12):1005-1011

12. Kenneson A, Cannon MJ (2007) Review and meta-analysis of the epidemiology of congenital cytomegalovirus (CMV) infection. Rev Med Virol 17(4):253-276

13. Ludwig A, Hengel H (2009) Epidemiological impact and disease burden of congenital cytomegalovirus infection in Europe. Euro Surveill 14(9):26-32

14. Malinger G, Lev D, Lerman-Sagie T (2011) Imaging of fetal cytomegalovirus infection. Fetal Diagn Ther 29:117-126

15. Steinlin MI, Nadal D, Eich GF, Martin E, Boltshauser EJ (1996) Late intrauterine Cytomegalovirus infection: clinical and neuroimaging findings. Pediatr Neurol 15:249-253

16. Revello MG, Gerna G (2002) Diagnosis and management of human cytomegalovirus infection in the mother, fetus, and newborn infant. Clin Microbiol Rev 15(4):680-715

17. De Paschale M, Agrappi C, Manco MT, Paganini A, Clerici P (2009) Incidence and risk of cytomegalovirus infection during pregnancy in an urban area of Northern Italy. Infect Dis Obstet Gynecol 2009: 206505

18. Tamer GS, Dundar D, Caliskan E (2009) Seroprevalence of Toxoplasma gondii, rubella and cytomegalovirus among pregnant women in western region of Turkey. Clin Invest Med 32(1):E43-E47

19. Ahlfors K, Ivarsson SA, Johnsson T, Svanberg L (1982) Primary and secondary maternal cytomegalovirus infections and their relation to congenital infection. Analysis of maternal sera. Acta Paediatr Scand 71(1):109-113

20. Gaytant MA, Steegers EA, Semmekrot BA, Merkus HM, Galama JM (2002) Congenital cytomegalovirus infection: review of the epidemiology and outcome. Obstet Gynecol Surv 57(4):245-256

21. de Villemeur AB, Gratacap-Cavallier B, Casey R, Baccard-Longère M, Goirand L, Seigneurin JM, Morand P (2011) Occupational risk for cytomegalovirus, but not for parvovirus B19 in child-care personnel in France. J Infect 63(6):457-467

22. de Vries JJ, Korver AM, Verkerk PH, Rusman L, Claas EC, Loeber JG, Kroes AC, Vossen AC (2011) Congenital cytomegalovirus infection in the Netherlands: birth prevalence and risk factors. J Med Virol 83(10): 1777-1782

23. Baldo V, Menegon T, Floreani A, Carletti M, Grella P, Trivello R (1999) Cytomegalovirus infection: a seroepidemiological study in a heterogeneous population of pregnant women. J Prev Med Hyg 40: $17-18$

24. Mustakangas P, Sarna S, Ammälä P, Muttilainen M, Koskela P, Koskiniemi M (2000) Human cytomegalovirus seroprevalence in three socioeconomically different urban areas during the first trimester: a population-based cohort study. Int J Epidemiol 29(3):587-591

25. Sheevani, Jindal N, Aggarwal A (2005) A pilot seroepidemiological study of cytomegalovirus infection in women of child bearing age. Indian J Med Microbiol 23(1):34-36

26. Tookey PA, Ades AE, Peckham CS (1992) Cytomegalovirus prevalence in pregnant women: the influence of parity. Arch Dis Child 67(7 Spec No):779-783

27. Picone O, Vauloup-Fellous C, Cordier AG, Parent du Châtelet I, Senat MV, Frydman R, Grangeot-Keros L (2009) A 2-year study on cytomegalovirus infection during pregnancy in a French hospital. BJOG 116(6):818-823

28. Gaytant MA, Galama JM, Semmekrot BA, Melchers WJ, Sporken JM, Oosterbaan HP, van Dop PA, Huisman A, Merkus HM, Steegers EA (2005) The incidence of congenital cytomegalovirus infections in The Netherlands. J Med Virol 76(1):71-75

29. Pembrey L, Raynor P, Griffiths P, Chaytor S, Wright J, Hall AJ (2013) Seroprevalence of cytomegalovirus, Epstein Barr virus and varicella zoster virus among pregnant women in Bradford: a cohort study. PLoS One 27(11):e81881

30. Alanen A, Kahala K, Vahlberg T, Koskela P, Vainionpää R (2005) Seroprevalence, incidence of prenatal infections and reliability of maternal history of varicella zoster virus, cytomegalovirus, herpes simplex virus and parvovirus B19 infection in South-Western Finland. BJOG 112(1):50-56

31. Francisse S, Revelard P, De Maertelaer V, Strebelle E, Englert Y, Liesnard C (2009) Human cytomegalovirus seroprevalence and risk of seroconversion in a fertility clinic population. Obstet Gynecol 114(2 Pt 1):285-291

32. Odland ML, Strand KM, Nordbø SA, Forsmo S, Austgulen R, Iversen AC (2013) Changing patterns of cytomegalovirus seroprevalence among pregnant women in Norway between 1995 and 2009 examined in the Norwegian Mother and Child Cohort Study and two cohorts from Sor-Trondelag County: a cross-sectional study. BMJ Open 3(9):e003066

33. de Ory F, Ramírez R, García Comas L, León P, Sagües MJ, Sanz JC (2004) Is there a change in cytomegalovirus seroepidemiology in Spain? Eur J Epidemiol 19(1):85-89

34. Ocak S, Zeteroglu S, Ozer C, Dolapcioglu K, Gungoren A (2007) Seroprevalence of Toxoplasma gondii, rubella and cytomegalovirus 
among pregnant women in southern Turkey. Scand J Infect Dis 39(3): 231-234

35. Munro SC, Hall B, Whybin LR, Leader L, Robertson P, Maine GT, Rawlinson WD (2005) Diagnosis of and screening for cytomegalovirus infection in pregnant women. J Clin Microbiol 43(9): 4713-4718

36. Fowler KB, Pass RF (2006) Risk factors for congenital cytomegalovirus infection in the offspring of young women: exposure to young children and recent onset of sexual activity. Pediatrics 118(2): e286-e292

37. Joseph SA, Béliveau C, Muecke CJ, Rahme E, Soto JC, Flowerdew G, Johnston L, Langille D, Gyorkos TW (2006) Cytomegalovirus as an occupational risk in daycare educators. Paediatr Child Health 11(7):401-407

38. Ford-Jones EL, Kitai I, Davis L, Corey M, Farrell H, Petric M, Kyle I, Beach J, Yaffe B, Kelly E, Ryan G, Gold R (1996) Cytomegalovirus infections in Toronto child-care centers: a prospective study of viral excretion in children and seroconversion among day-care providers. Pediatr Infect Dis J 15(6):507-514

39. Ashrafunnessa, Khatun S, Islam MN, Rashid MH (2009) Seroprevalence of cytomegalovirus antibody in antenatal population in Bangladesh. Bangladesh Med Res Counc Bull 35(3):110-112

40. Kolo RL, Umoh VJ, Jatau ED, Ella EE (2013) Seroprevalence of cytomegalovirus among antenatal patients attending primary health centres in some parts of Kaduna State, Nigeria. SAJEB 3(1):43-48
41. Soto JC, Delage G, Vincelette J, Belanger L (1994) Cytomegalovirus infection as an occupational hazard among women employed in daycare centers. Pediatrics 94(Suppl):S1031

42. Jahan M, Tabassum S, Aziz A, Ahmed M, Islam N (2010) Transfusion associated CMV infection: transfusion strategies for high risk patients. Bangladesh J Med Microbiol 4(2):24-27

43. Kothari A, Ramachandran VG, Gupta P, Singh B, Talwar V (2002) Seroprevalence of cytomegalovirus among voluntary blood donors in Delhi, India. J Health Popul Nutr 20(4):348-351

44. Njeru DG, Mwanda WO, Kitonyi GW, Njagi EC (2009) Prevalence of cytomegalovirus antibodies in blood donors at the National Blood Transfusion Centre, Nairobi. East Afr Med J 86(12 Suppl):S58-S61

45. Ziemann M, Krueger S, Maier AB, Unmack A, Goerg S, Hennig H (2007) High prevalence of cytomegalovirus DNA in plasma samples of blood donors in connection with seroconversion. Transfusion 47(11):1972-1983

46. Dollard SC, Staras SA, Amin MM, Schmid DS, Cannon MJ (2011) National prevalence estimates for cytomegalovirus IgM and IgG avidity and association between high IgM antibody titer and low IgG avidity. Clin Vaccine Immunol 18(11):1895-1899

47. Correa CB, Kourí V, Verdasquera D, Martínez PA, Alvarez A, Alemán Y, Pérez L, Viera J, González R, Pérez E, Moro I, Navarro MA, Melin P (2010) HCMV seroprevalence and associated risk factors in pregnant women, Havana City, 2007 to 2008. Prenat Diagn 30(9):888-892 